\title{
Erratum
}

Mahmoud Soliman Abdel-Hamid, Amr Fouda*, Hesham Kamal Abo El-Ela, Abbas A. El-Ghamry, Saad El-Din Hassan*

\section{Erratum to "Plant growth-promoting properties of bacterial endophytes isolated from roots of Thymus vulgaris $L$. and investigate their role as biofertilizers to enhance the essential oil contents"}

https://doi.org/10.1515/bmc-2021-0025

received January 28, 2022; accepted January 28, 2022

In the published article "Plant growth-promoting properties of bacterial endophytes isolated from roots of Thymus vulgaris $\mathrm{L}$. and investigate their role as biofertilizers to enhance the essential oil contents" (https://doi.org/10. 1515/bmc-2021-0019), the affiliation of the corresponding author was entered incorrectly. The authors apologize for any inconvenience that it may have caused.

The correct affiliation is as follows:

Amr Fouda, Botany and Microbiology Department, Faculty of Science, Al-Azhar University, Cairo 11884, Egypt, e-mail: amr_fh83@azhar.edu.eg.

\footnotetext{
* Corresponding author: Amr Fouda, Botany and Microbiology Department, Faculty of Science, Al-Azhar University, Cairo 11884, Egypt, e-mail: amr_fh83@azhar.edu.eg

* Corresponding author: Saad El-Din Hassan, Botany and Microbiology Department, Faculty of Science, Al-Azhar University, Cairo 11884, Egypt, e-mail: saad.el-din.hassan@umontreal.ca Mahmoud Soliman Abdel-Hamid, Hesham Kamal Abo El-Ela: Soil Fertility and Microbiology Department, Desert Research Center, El-Mataria, Cairo, Egypt

Abbas A. El-Ghamry: Botany and Microbiology Department, Faculty of Science, Al-Azhar University, Cairo 11884, Egypt
} 